\title{
Steam temperature stability in a direct steam generation solar power plant
}

\author{
Jürgen Birnbaum ${ }^{\mathrm{a}}$, Jan Fabian Feldhoff ${ }^{\mathrm{b}, *}$, Markus Fichtner ${ }^{\mathrm{a}}$, Tobias Hirsch ${ }^{\mathrm{c}}$, \\ Markus Jöcker ${ }^{\mathrm{d}}$, Robert Pitz-Paal ${ }^{\mathrm{e}}$, Gerhard Zimmermann ${ }^{\mathrm{a}}$ \\ ${ }^{\text {a }}$ Siemens AG, Sector Energy, Erlangen, Germany \\ ${ }^{\mathrm{b}}$ German Aerospace Center (DLR), Institute of Technical Thermodynamics, Pfaffenwaldring 38-40, 70569 Stuttgart, Germany \\ ${ }^{\mathrm{c}}$ German Aerospace Center (DLR), Institute of Technical Thermodynamics, Stuttgart, Germany \\ ${ }^{\mathrm{d}}$ Siemens AG, Sector Energy, Fingspong, Sweden \\ ${ }^{\mathrm{e}}$ German Aerospace Center (DLR), Institute of Technical Thermodynamics, Cologne, Germany
}

Available online 30 October 2010

Communicated by: Associate Editor Markus Eck

\begin{abstract}
Direct steam generation (DSG) is one alternative to the current oil-based parabolic trough solar thermal power plants. Within the German research project ITES, the dynamic behavior of a DSG collector field and the interactions with the conventional power block are assessed in detail. A transient solar field model developed by DLR is used to simulate the steam temperature behavior. Artificial irradiance disturbances as well as real irradiance data are used as input to the system. The resulting main steam temperature gradients are then analyzed by Siemens considering the standards for steam turbines.

This paper presents the transient simulation results of the steam temperature as well as the corresponding results of the steam turbine analysis. It is found that the occurring temperature gradients are challenging for a safe turbine operation, if a conservative control system is used. Therefore, the use of an additional thermal inertia to stabilize the steam temperature is suggested. Its impact is also analyzed and discussed in this paper.
\end{abstract}

(c) 2010 Elsevier Ltd. All rights reserved.

Keywords: Solar thermal power plant; Parabolic trough; Direct steam generation; Transient simulation; Steam turbine

\section{Introduction}

Research on direct steam generation (DSG) parabolic trough dates back to the 1980 s when alternatives to the oil based technology were evaluated. First works concentrated on the two-phase flow phenomena in the horizontal evaporator pipes and lead to the design and erection of the DISS test loop at the Plataforma Solar de Almería (Zarza et al., 2004). The feasibility and safe operation of the technology

\footnotetext{
* Corresponding author. Tel.: +49(0)711 6862 362; fax: +49 (0)711 6862 8032.

E-mail address: jan.feldhoff@dlr.de (J.F. Feldhoff).
}

was shown in more than $8000 \mathrm{~h}$ of operation until today (Eck et al., 2003). Following projects dealt with the design of a small demonstration plant where technical questions like the water/steam separators are addressed (Eck et al., 2008; Hirsch and Eck, 2008). Control concepts have been developed for the DSG (Koch et al., 2007; Valenzuela et al., 2005). A recent study comparing the conventional oil system with the direct steam generation system reveals about $11 \%$ lower levelized electricity costs for the direct steam generation (Eck et al., 2008; Feldhoff et al., 2010). With the technology close to commercial application some remaining technical questions are in the focus today. One of them is the operation together with the steam turbine which is addressed in this paper. Another important aspect 


\section{Nomenclature}

DNI direct normal irradiance $\left[\mathrm{W} / \mathrm{m}^{2}\right]$

DSG direct steam generation

ITES development and integration of thermal energy storage for parabolic trough power plants with direct steam generation
TES thermal energy storage is the availability of a thermal storage system (Birnbaum et al., 2008a).

\section{Plant configuration}

Different power plant configurations have been designed during the ITES project. The configuration chosen for the analysis presented here has main steam parameters of $400{ }^{\circ} \mathrm{C}$ and $110 \mathrm{bar}$. The following sections cover the plant's layout as well as models and assumptions of the solar field and the power block.

\subsection{Plant layout}

The power plant is designed for a gross electricity output of $50 \mathrm{MW}_{\mathrm{el}}$. The solar field is divided into four subfields, each of which consisting of 116 EuroTrough collectors of $150 \mathrm{~m}$ length (Price et al., 2002). The solar field is operated in recirculation mode, which means that each subfield is divided into an evaporation and superheating section by a central water/ steam separator as shown in Fig. 1. The evaporation section has 22 parallel loops of four collectors in series. The superheating section consists of 14 parallel loops of two collectors in series. Before the last collector of each superheating loop a spray attemperator is installed. A detailed description of the layout can be found in Birnbaum et al. (2008b).

\subsection{Solar field modeling}

The solar field was modeled with the software Dymola/Modelica. To simplify the solar field model, the

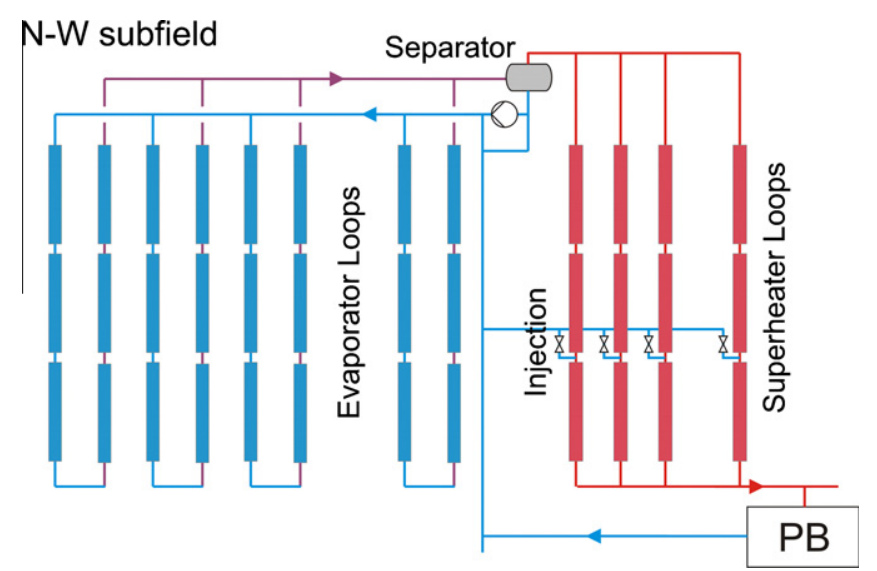

Fig. 1. Layout of a recirculation mode subfield with central field separator. approach of a representative loop is chosen. In this model, the water enters the loop, is partly evaporated and then transported to the separator. The condensate is recirculated with a constant mass flow. The saturated steam is fed to the superheating collectors. To allow for modeling only one loop, the mass flow leaving the separator has to be scaled according to the proportion of evaporation to superheating loops (a factor of 22/14 in our case). The representative loop model is spatially discretized and onedimensional. It considers conservation of heat and mass balances as well as the steady-state momentum balance based on pressure loss correlations (Hirsch et al., 2005).

For the solar field headers, detailed analogous models are used. Assuming a common design velocity for all sections of a header, the diameter changes from section to section, and with it the specific pressure drops. For the simulation model, a pipe flow element is used representing the header section to a loop in the middle of the subfield. The diameter of this pipe is chosen in a way that half of the overall header design pressure loss is reached at half the mass flow for the subfield. For modeling the evaporation collecting header, the down time of the header must be considered. In addition, the thermal inertia is considered for the header between row outlet and power block inlet, as it has a significant influence on main steam temperature.

The control scheme for regulating the solar field outlet temperature is shown in Fig. 2. The outlet temperature and the set point take the lead of the cascade controller. The track with the middle temperature of the last collector as input then sets the new valve position of the injector. The parameters of the controller are adapted based on analytical models (Koch et al., 2007). Feed water mass flow is adapted to the actual steam production with a small time lag.

\subsection{Power block modeling}

The power block is operated in modified sliding pressure mode (Birnbaum et al., 2008b), which is advantageous for thermal energy storage (TES) integration. For the per-

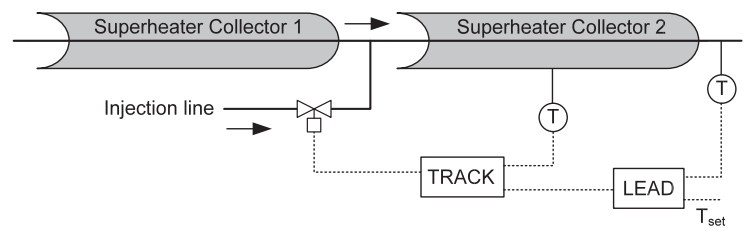

Fig. 2. Control scheme for superheating temperature controller. 
formed transient modeling, TES is simulated as a heat sink. If the appearing main steam flow from the solar field exceeds the maximum power block mass flow, the nominal power block mass flow is fed to the turbine and the rest to the heat sink. The discharge of the TES is not considered for the transient analysis since the TES is not supposed to impress short-time temperature fluctuations.

The power block characteristics like feed water temperature, back pressure of the turbine and power output are simulated according to a power block layout based on a generic model of the Siemens Steam Turbine SST-700. For the transient modeling, especially the final feed water temperature is important. This depends on current load and main steam temperature of the power block.

\section{Transient behavior of the solar field}

The transient reaction on irradiance fluctuations is described in the following sections. Theoretical irradiance disturbances show the general behavior before real irradiance data is used for the simulations. In addition, the influence of spatially distributed irradiance signals is analyzed.

\subsection{Single row with stepwise excitation}

For the transient study, a system at a direct normal irradiance (DNI) of $550 \mathrm{~W} / \mathrm{m}^{2}$ is assumed as initial state. Then, a step function reduces the irradiance, and after $120 \mathrm{~s}$ or $600 \mathrm{~s}$ the initial irradiance is recovered again by a ramp of $10 \mathrm{~s}$. The irradiance disturbance is either $50 \%$ or $100 \%$ of the initial irradiance, resulting in DNI values of 275 or $0 \mathrm{~W} / \mathrm{m}^{2}$. The disturbance can be imposed on the evaporation and superheating sections separately. Furthermore, a time delay between the disturbances of evaporation and superheating section is possible.

Figs. 3 and 4 depict typical transient behaviors of the solar field. All shown disturbances of the evaporator are $50 \%$ and their duration is $600 \mathrm{~s}$ or $10 \mathrm{~min}$, respectively. The time scale of the experiments was chosen to have the evaporation disturbances all at the same time. The dotted lines in both figures show the same case in which the whole solar field experiences a homogeneous $50 \%$ irradiance drop.

Looking at this homogeneous disturbance case (dotted lines), the disturbance starts shortly after $10 \mathrm{~min}$. During the first seven minutes (until about minute 17) the mass flow is not instantaneously but steadily reduced, indicating the effect of thermal inertia in the evaporator. After about 7 min the mass flow drops steeply which marks the point where power block operation switches from sliding to constant pressure mode. When the initial irradiance is available again (after $20 \mathrm{~min}$ in Fig. 3), the temperature controller causes an overshoot of the outlet temperature. Temperature gradients of -8 to $11 \mathrm{~K} / \mathrm{min}$ appear and an overshooting for $220 \mathrm{~s}$ above $420^{\circ} \mathrm{C}$ is found.

In Fig. 3 also the impact of different disturbance magnitudes in the superheating section is shown. Main steam mass flows differ only slightly. However, main steam temperatures
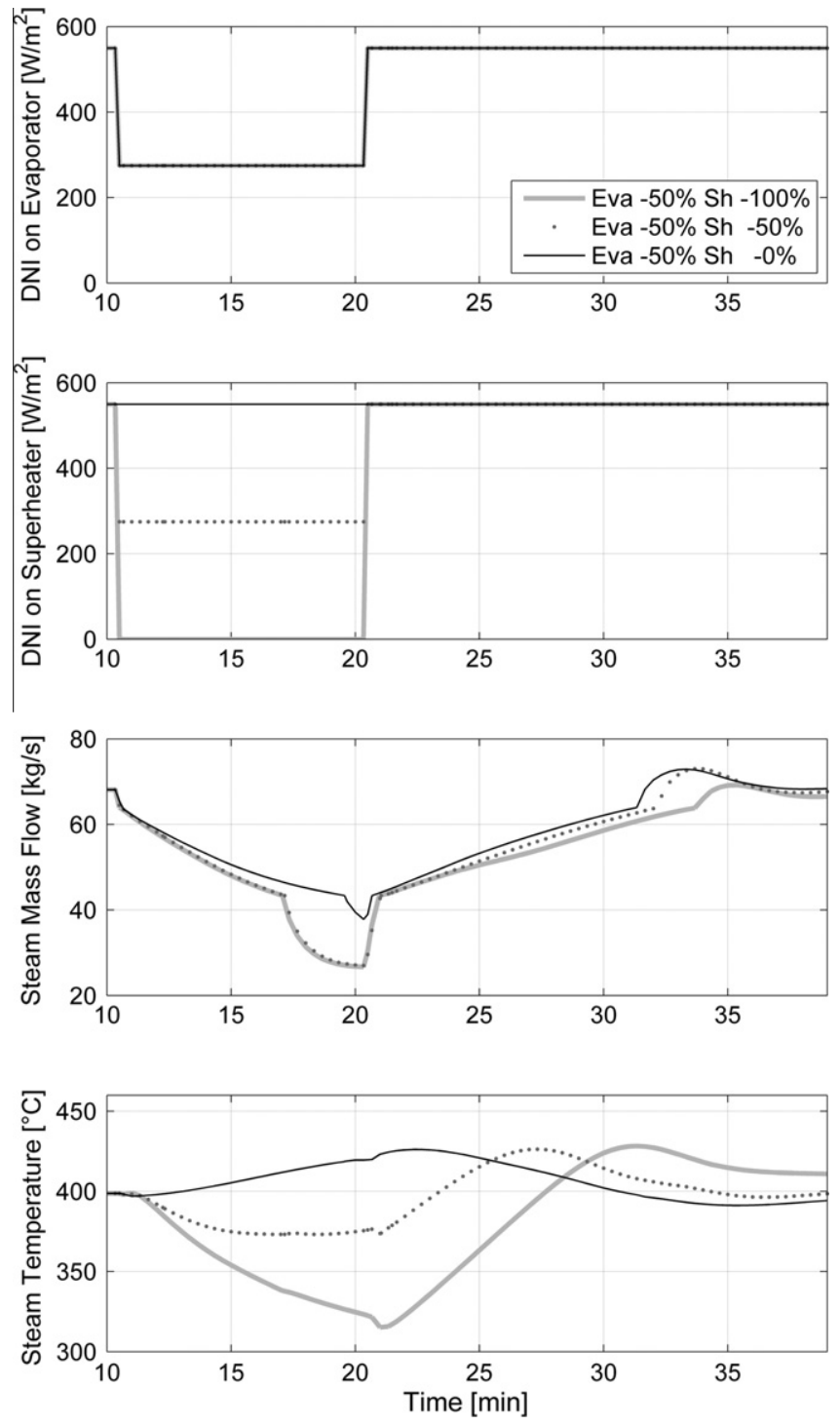

Fig. 3. Different combinations of artificial irradiance disturbances on evaporation and superheating section.

behave obviously different. The case with no superheating disturbance (black line in Fig. 3) leads to an increase in main steam temperature, because the same amount of solar energy is available on the superheater loops for a decreasing amount of saturated steam. The mass flow of injected water is steadily risen, such that in total the main steam temperature rises slowly. For the case with $100 \%$ superheater disturbance (gray line in Fig. 3), no solar energy on the superheater loops is available any more, such that the energy for superheating in the first minutes only comes from the thermal inertia of the superheating loops themselves until the saturation temperature is reached also at the outlet.

Fig. 4 shows the impact of time delays between the irradiance drops in evaporation and superheating sections. All evaporation disturbances have the same magnitude and are imposed at the same time. If the disturbance in the superheating section appears before the one in the evaporation section $(-600 \mathrm{~s}$ case, i.e. $600 \mathrm{~s}$ before evaporation disturbance, gray line in Fig. 4), the mass flow at first stays 

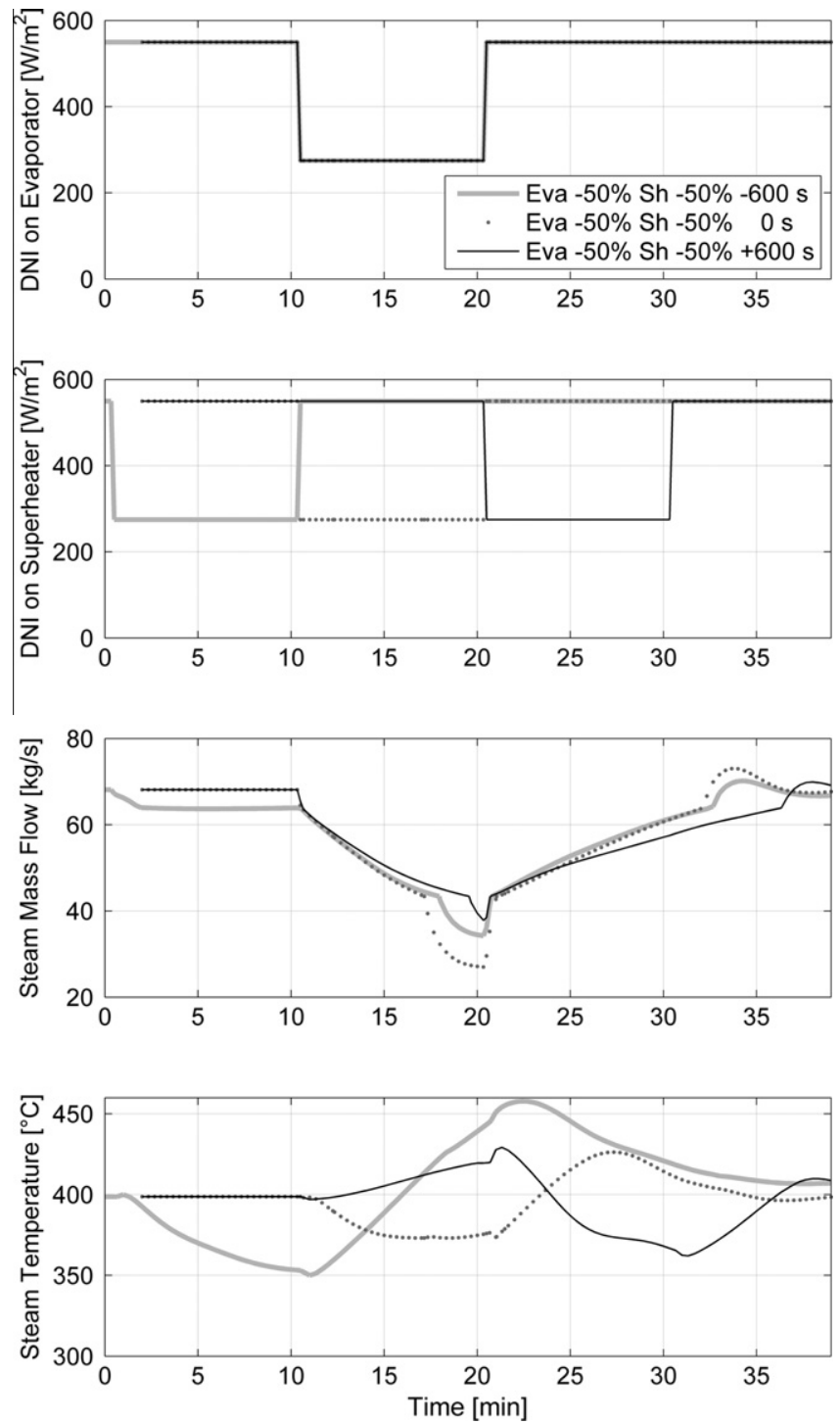

Fig. 4. Effect of disturbance time delays between evaporation and superheating section.

stable and the temperature decreases. If the disturbance occurs at first in the evaporation section and afterwards in the superheating section ( $+600 \mathrm{~s}$ case), the behavior is vice versa. At first the mass flow decreases and the temperature increases. However, after the evaporation disturbance and with the superheating disturbance (after 20 min in Fig. 4) two effects amplify the temperature undershoot. One is the temperature drop due to the mass flow increase and the second is the temperature drop due to the irradiance drop in the superheating section. Such disadvantageous time delays can be a source for high temperature deviations. Observed temperature gradients are in the range of $4-29 \mathrm{~K} / \mathrm{min}$. Typical pressure gradients range from 1 to $6 \mathrm{bar} / \mathrm{min}$.

Summing up the effects, it can be learned that the steam mass flow is primarily linked to the irradiance conditions in the evaporation section, while the steam temperature's dynamic behavior is mainly driven by the irradiance conditions of the superheating section.

\subsection{Single row with measured diurnal variation}

In addition to the artificial ramp-type disturbances, the behavior of the solar field due to measured diurnal irradiance variations is assessed to show a typical real plant behavior. As an example, the irradiance data of Tabernas, Spain $\left(37.16^{\circ} \mathrm{N}, 2.36^{\circ} \mathrm{W}\right)$ of February 27,2002 are used. The irradiance is assumed homogeneous over the whole solar field. The steam temperature and mass flow behavior is shown in Fig. 5. The dotted line in the mass flow diagram indicates the nominal power block mass flow.

During this afternoon, temperature gradients of -21 to $17 \mathrm{~K} / \mathrm{min}$ and pressure gradients of -10 to $8 \mathrm{bar} / \mathrm{min}$ are observed. The temperature of $420^{\circ} \mathrm{C}$ is exceeded for $690 \mathrm{~s}$ and $430{ }^{\circ} \mathrm{C}$ for $100 \mathrm{~s}$. Temperatures below $380^{\circ} \mathrm{C}$ appear for $530 \mathrm{~s}$ and below $370{ }^{\circ} \mathrm{C}$ for $290 \mathrm{~s}$. The total temperature range varies by about $72 \mathrm{~K}$.

\subsection{Averaging effects for multi-row superheater}

In the last section, a homogeneous irradiance on the whole solar field was considered. However, solar power plants are distributed over large areas and it is likely that some areas of the solar field differ in irradiance. To assess the temperature stability, the irradiance on the superheating section has the most influence. Therefore, the averaging effect of spatially distributed irradiance signals is analyzed only for the superheating section.

It is assumed that the irradiance fluctuations are mainly caused by passing clouds and are moving with cloud speed, which can be extrapolated from wind measurements (Gasch and Twele, 2002) on the Tabernas site. For a simple post-processing approach, it is further assumed that the simulated main steam temperature from the diurnal simulations of Section 3.2 move with signal speed from the west to the east end of the superheating collector field, a distance of $484 \mathrm{~m}$. For each time step, an average outlet temperature is calculated and illustrated in Fig. 6. If a velocity of $1 \mathrm{~m} / \mathrm{s}$ is assumed, the effect is positive for the overall temperature stability. Temperatures gradients are reduced to $\pm 8 \mathrm{~K} / \mathrm{min}$. Pressure gradients as well as the absolute temperature range are also reduced significantly. Nevertheless, at a velocity of $16 \mathrm{~m} / \mathrm{s}$ the difference to the single loop simulation becomes already very small and negligible.

The wind speed data suggested a cloud velocity of about $16 \mathrm{~m} / \mathrm{s}$ or more for the assessed day. Although a simplified model is used for this assessment, it can be concluded that an averaging effect in real plants can be expected only with very small cloud speeds. However, on cloudy days higher wind speeds are more likely. Therefore, using a representative single loop model is a reasonable approach for simulating the transient steam temperature behavior of the whole plant.

\section{Transient analysis of turbine}

The requirements a steam turbine has to fulfill in a conventional fossil fired power plant are different to the 

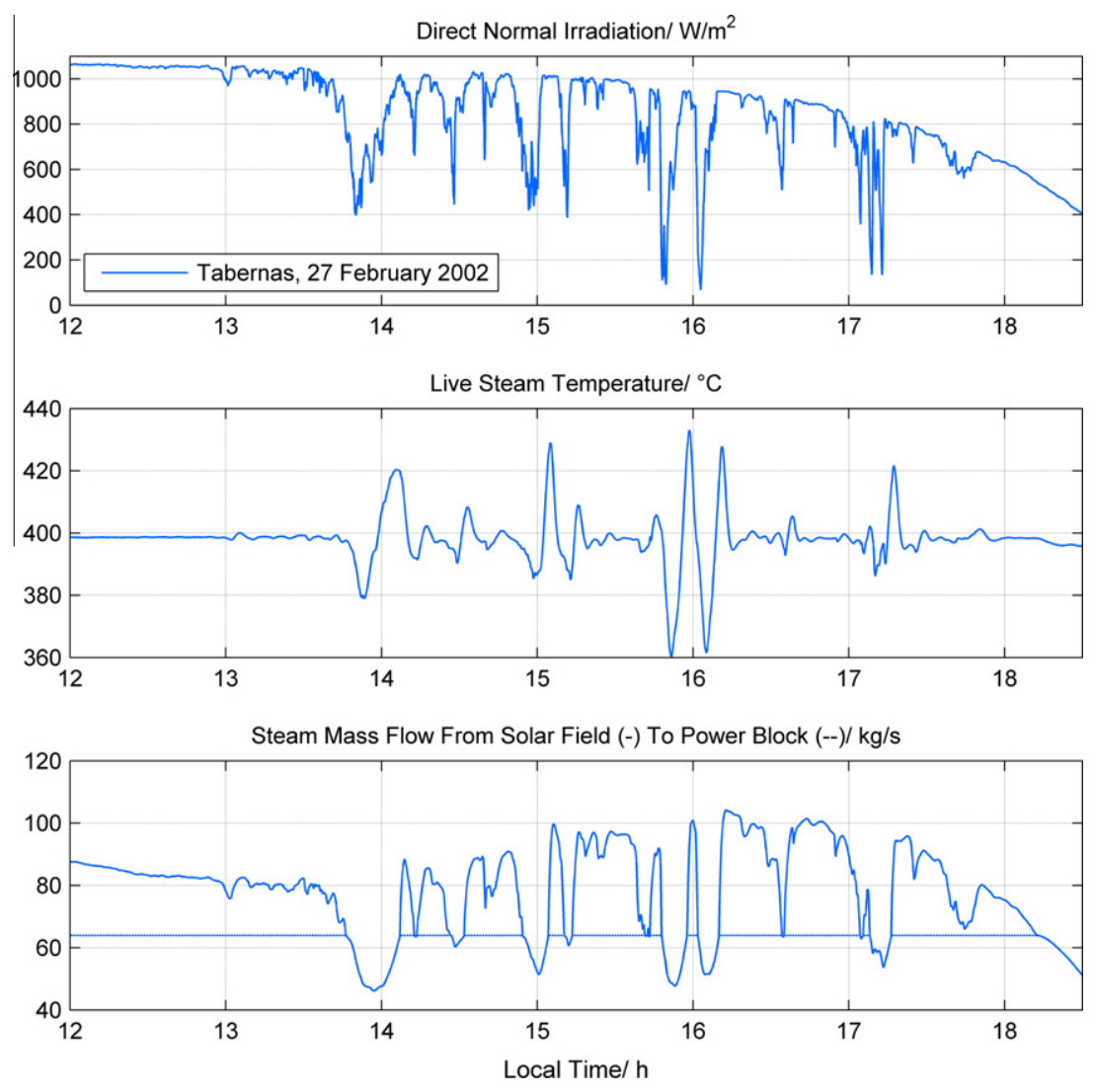

Fig. 5. Simulated solar field behavior under measured direct normal irradiance.

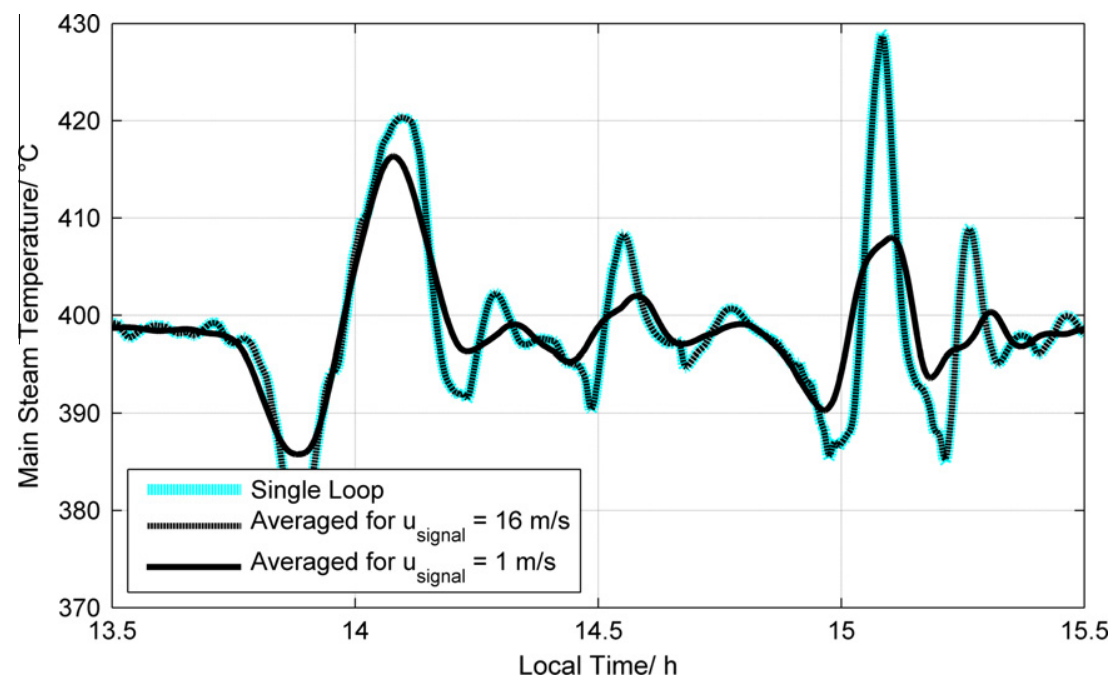

Fig. 6. Main steam temperature behavior of single loop and as a result of moving irradiance signals.

requirements in a solar thermal power plant. One main difference is caused by the cycling rate of start-ups and shut downs, which varies from several times a year for a big base load nuclear power plant to at least one cycle a day for a solar thermal plant. In addition, the latter has to follow fast and frequent load alternations. Combined cycle power plants can be operated in daily cycling mode and, therefore, so can be the steam turbines used in this type of plant. But contrary to solar thermal power plants, the load gradients and the main steam parameters in a combined cycle power plant can be kept within certain limits due to the controlled heat input.

To determine, if state-of-the-art steam turbines can fulfill the special requirements of a solar thermal power plant, 
first, the operation limits of steam turbines are to be described, and second, the transients of the steam delivered by the solar field are to be analyzed.

\subsection{Limitations of steam turbine}

As steam turbines have been operated for more than 100 years, a quality standard for steam turbines (IEC, 1991) has been established, which has to be matched by every commercially operated turbine. In this standard, the specification of a steam turbine is described.

Looking at the relevant parts of the standard, which are characterizing the dynamic behavior of a steam turbine (e.g. main steam temperature), limits regarding steam quality have to be achieved.

Table 1 shows the limits for the main steam temperature and pressure, which are allowed to be exceeded for a certain duration. However, the annual average of pressure and temperature deviations has to be equal or smaller than the rated conditions. The absolute limits for temperature and pressure, which should not be exceeded, are $28 \mathrm{~K}$ and $120 \%$, respectively, above the rated conditions. In addition, turbine operation with a rotating speed between $98 \%$ and $101 \%$ of the rated rotating speed must be possible without any limitations.

The allowable steam transients in operation are not mentioned within this standard. For the main steam pressure the transients are not critical. Normally, if the main steam pressure is too high, the safety valve will close in less than $1 \mathrm{~s}$. Subsequently, the pressure within the turbine is decreasing immediately. So pressure transients within operation cannot reach this transient. As a rule of thumb, main steam temperature transients smaller than $5 \mathrm{~K} / \mathrm{min}$ for turbines in the range of 50-150 MW can be followed by the turbine. Typically, the allowable main steam temperature transients vary between the different turbine types and manufacturers.

Furthermore, the operation limits within the turbine, e.g. allowable temperature difference between the steam and the casing or the rotor, are specific values for each turbine and manufacturer. Therefore, they cannot be discussed in general.

\subsection{Analysis of solar field response}

To analyze the dynamic behavior of the steam turbine, a Dymola/Modelica model was set up for the turbine. The details of the model and the modeling approach can be found in Birnbaun et al. (2009). Different load cases were analyzed: artificial irradiance disturbances and the already above discussed characteristic cloudy weather day in Tabernas. The focus was set on the characteristic cloudy day and the limits of main steam parameters.

Fig. 7 shows the steam transients and the excess temperatures occurring at the turbine inlet and the applicable limits for the main steam temperature described in Section 4.1 for the typical cloudy weather day. During the day, the rated main steam temperature is exceeded for several times. The $<+14 \mathrm{~K}$ and the $<+8 \mathrm{~K}$ excess temperature limits are exceeded for $15 \mathrm{~min}$ and $25 \mathrm{~min}$, respectively, which is not critical for one day but has to be considered over a whole year. The critical $+28 \mathrm{~K}$ excess temperature limit is exceeded two times a day with an overall duration of $4 \mathrm{~min}$. This normally means that the turbine safety valve would be closed and the turbine would trip. Such turbine trips typically have two impacts: a reduction of the turbine lifetime and, of course, a restart of the plant, which results in a discontinuous electricity production. The maximal temperature transient occurring on this day is $13.2 \mathrm{~K} / \mathrm{min}$, which is far away from the allowed transient of $<5 \mathrm{~K} / \mathrm{min}$. Again, this high transient would lead to a significant reduction of the turbine's lifetime.

As mentioned in Section 4.1, the limits are always defined for turbine operation over one year. Montes et al. (2009) shows an interesting approach, how a typical year can be characterized with only a limited number of typical days. This approach is also used here to analyze whether the critical temperature limits over one year are followed or exceeded.

For Tabernas, Montes determines 189 cloudy weather days during a typical year, taking into account that in January and December nearly no electricity can be produced. These typical cloudy weather days are characterized here by the exemplary day described above. With this data, the yearly behavior regarding the main steam temperature limits can be determined.

Table 1

Limits of main steam temperature and pressure at turbine inlet according to standard.

\begin{tabular}{|c|c|c|}
\hline Parameter & Limit & Duration \\
\hline Turbine inlet temperature & $\begin{array}{l}\text { Rated temperature } \\
<+8 \mathrm{~K} \text { exceeding rated temperature } \\
<+14 \mathrm{~K} \text { exceeding rated temperature } \\
<+28 \mathrm{~K} \text { exceeding rated temperature } \\
+28 \mathrm{~K} \text { exceeding rated temperature }\end{array}$ & $\begin{array}{l}\text { Annual average must be the rated temperature or below } \\
\text { Annual average must be maintained } \\
\text { Annual average must be maintained and accumulated duration }<400 \mathrm{~h} \\
\text { per year } \\
\text { Annual average must be maintained, accumulated duration }<80 \mathrm{~h} \text { per } \\
\text { year, max. duration }<15 \text { min } \\
\text { Not allowed to exceed }\end{array}$ \\
\hline
\end{tabular}




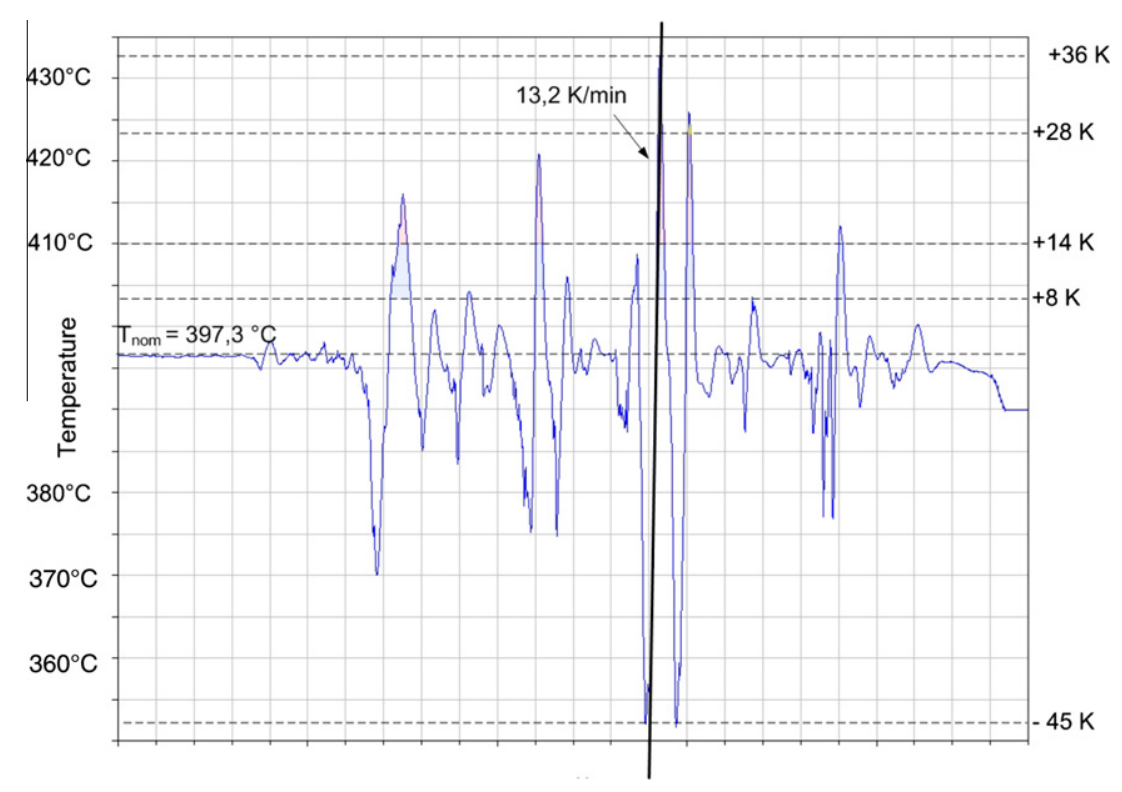

Fig. 7. Main steam excess temperature and maximal transient.

Table 2 shows the results of the annual duration of an exceeded main steam temperature and the corresponding limits. The annual accumulated duration of the main steam temperature regarding the excess temperature limits of $+8 \mathrm{~K}$ and $+14 \mathrm{~K}$ is clearly below the given limits and, therefore, no critical operation is expected. However, the accumulated duration of the main steam temperature exceeding $+28 \mathrm{~K}$ is above $13 \mathrm{~h} /$ year. This impacts the stable operation of the whole plant significantly.

\section{Reduction of transients by additional thermal inertia}

In order to reduce the fast transients induced by disturbances in irradiance, an additional thermal inertia can be applied. In this study, the effect of a pipe bundle arranged in the main steam line between solar field and turbine is analyzed. The constructional parameters are varied according to Table 3.
Fig. 7 shows the effect of the different pipe bundle configurations on the range of the steam temperature and the peak temperature gradients for the irradiance time series used in Section 3.2/Fig. 5. Results are plotted against the steel mass since this quantity is representative for the thermal inertia and also the investment costs. From Fig. 8a it can be derived that the temperature fluctuation range of the solar field of $72 \mathrm{~K}$ during the assessed afternoon is significantly reduced but not vanished by the pipe bundle. The way the steel mass is applied has only minor importance for the effect. It has to be noted that in a preliminary study inner diameters of more than $100 \mathrm{~mm}$ are found to become less effective since the heat transfer coefficient decreases with flow velocity. A similar effect is observed for very thick pipe walls. In such pipes the ratio of heat transfer surface to wall thickness is too small to result in a high enough heat transfer. This trend is indicated in Fig. 8a for the steel mass above 100 tons.

Table 2

Duration of exceeded temperature limits over a typical year.

\begin{tabular}{lllll}
\hline Excess temperature limit & Allowed duration (h/a) & Duration per day $(\mathrm{min})$ & Duration per year & Operation \\
\hline$<+14 \mathrm{~K}$ & 400 & 15 & $\sim 240 \mathrm{~h}$ & Not critical \\
$<+28 \mathrm{~K}$ & 80 & 12 & $\sim 40 \mathrm{~h}$ & Not critical \\
$+28 \mathrm{~K}$ & 4 & $\sim 13 \mathrm{~h}$ & Impact on stable electricity production and \\
& 0 & & lifetime \\
\hline
\end{tabular}

For stable electricity production regarding the limits of the turbine, this analysis shows two critical issues: the main steam temperature transient and the main steam excess temperature $>+28 \mathrm{~K}$.

Table 3

Pipe bundle constructional variations in four parameters (italic: basic design).

\begin{tabular}{lllll}
\hline Length of pipes & $15 \mathrm{~m}$ & $22.5 \mathrm{~m}$ & $30 \mathrm{~m}$ & $37.5 \mathrm{~m}$ \\
Number of parallel pipes & 15 & 23 & 30 & 37 \\
Inner diameter & $56.5 \mathrm{~mm}$ & $70 \mathrm{~mm}$ & $80 \mathrm{~mm}$ & 45 \\
Wall thickness & $16.8 \mathrm{~mm}$ & $24 \mathrm{~mm}$ & $30 \mathrm{~mm}$ & $98 \mathrm{~mm}$ \\
\hline
\end{tabular}



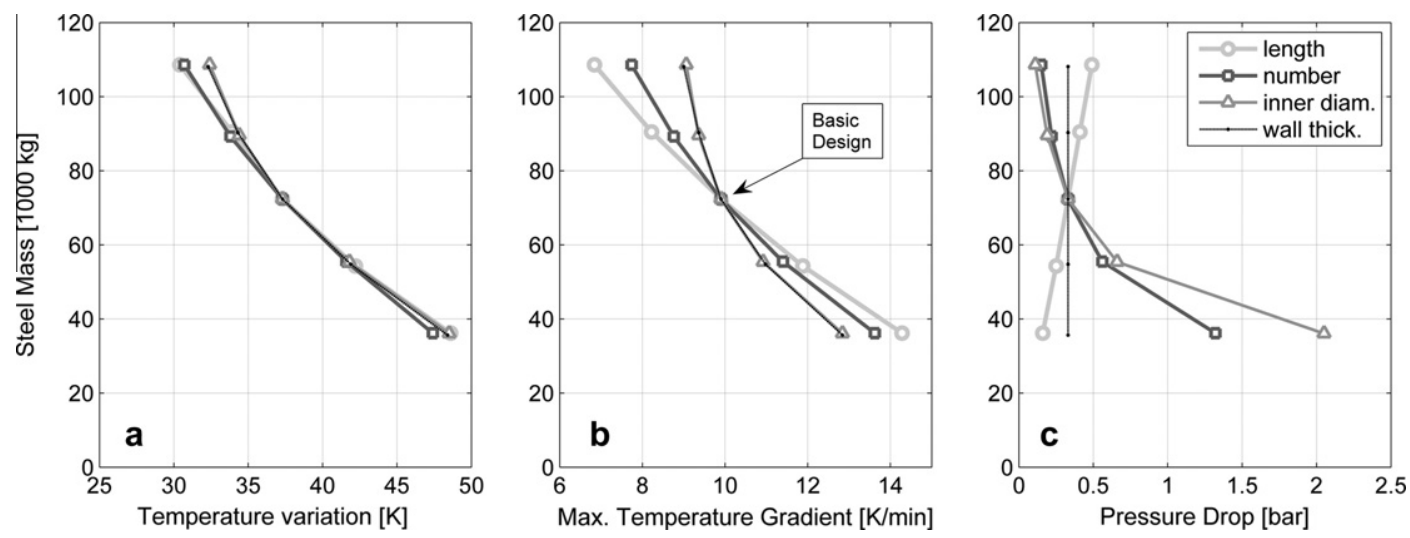

Fig. 8. Effect of parameter variations from Table 3.

Fig. $8 \mathrm{~b}$ gives valuable information in which way the steel mass should be applied in an optimal way. In order to decrease the initial peak temperature gradient of $21 \mathrm{~K} / \mathrm{min}$, steel mass should primarily be employed to increase the number of parallel pipes or to enlarge their length. From the basic design steel mass (70 tons) on, inner diameter and wall thickness enlargement result only in minor improvements. The reason is again the limitation of either the inner surface's convective or the wall's conductive heat transfer. Diagram $7 \mathrm{~b}$ has to be evaluated together with diagram $7 \mathrm{c}$ showing the resulting pressure drops in the pipe segments. The solution with best thermodynamic performance suffers from the largest additional pressure drop. Increasing the number of parallel pipes appears to be the solution on hand, although a final decision will only be possible on a detailed design and cost estimate.

\section{Conclusions and outlook}

This paper summarizes the results for the steam temperature stability of a collector field equipped with spray attemperators to control the main steam temperature. The transient solar field behavior is assessed for different irradiance disturbances. A study with artificial disturbances shows that high deviations from the desired steam temperature occur, if the amplitude of the irradiance drop is high or if a disadvantageous time delay between evaporation and superheating disturbance occurs. Observed temperature gradients are in the range of 4 $29 \mathrm{~K} / \mathrm{min}$. Characteristic pressure gradients range from 1 to $6 \mathrm{bar} / \mathrm{min}$.

The assessment of temperature and pressure gradients on a cloudy day in Tabernas, Spain, was performed with measured irradiance data. The results for a representative single loop suggest that the resulting temperature behavior does not completely meet the standards for steam turbines. Temperature gradients are expected to be critical and the temperature limit of $+28 \mathrm{~K}$ above the rated temperature is exceeded longer during one year than allowed for the steam turbine. It was further confirmed, that an averaging effect of spatially distributed irradiance signals, as it would occur due to the large size of the collector field, is not expected to lower the temperature gradients significantly.

Applying an additional thermal inertia after the solar field helps to reduce the challenging temperature gradients and overshoots to an acceptable range for the steam turbine. This buffer storage needs a high power capacity to react quickly, while the total energy capacity of the system is of lower importance. However, the pressure drop and cost impact of this buffer storage has to be considered.

Another alternative for stabilizing the main steam temperature can be an additional spray attemperator before the turbine inlet. This option was not covered in this paper, but will be assessed in future studies.

\section{Acknowledgements}

The authors would like to thank the German Ministry for the Environment, Nature Conservation and Nuclear Safety for the financial support given to the ITES project (Contract No 16UM0064).

\section{References}

Birnbaum, J., Eck, M., et al., 2008. A direct steam generation solar power plant with integrated thermal storage. In: Proceedings of the 14th Bienial SolarPACES Symposium. Las Vegas, USA.

Birnbaum, J., Hirsch, T., et al., 2008. A concept for future parabolic trough based solar thermal power plants. In: Proceedings of the 15 th International Conference on the Properties of Water and Steam. Berlin, Germany.

Birnbaum, J., Joecker, M., Link, K., 2009. Simulation of the dynamic behavior of steam turbines with Modelica. In: Proceedings of the 7th International Modelica Conference. Como, Italy.

Eck, M., Zarza, E., et al., 2003. Applied research concerning the direct steam generation in parabolic troughs. Solar Energy 74 (4), 341-351.

Eck, M., Schmidt, H., et al., 2008. Field test of water-steam separators for direct steam generation in parabolic troughs. Journal of Solar Energy Engineering 130 (1), 011002-1-011002-6.

Eck, M., Benz, N., et al., 2008. The potential of direct steam generation in parabolic troughs - results of the german project DIVA. In: Proceedings of the 14th Biennial CSP SolarPACES Symposium. Las Vegas, USA.

Feldhoff, J.F., Benitez, D., et al., 2010. Economic potential of solar thermal power plants with direct steam generation compared with HTF plants. Journal of Solar Energy Engineering 132 (4), 041001041009 . 
Gasch, R., Twele, J., 2002. Wind Power Plants - Fundamentals, Design, Construction and Operation. Solarpraxis, James \& James, Berlin, London.

Hirsch, T., Eck, M., 2008. Design of a phase separation system for a direct steam generation parabolic trough collector field. Journal of Solar Energy Engineering 130 (1), 011003-1-011003-6.

Hirsch, T., Eck, M., Steinmann, W.D., 2005. Simulation of transient twophase flow in parabolic trough collectors using Modelica. In: Proceedings of the 4th International Modelica Conference. Hamburg, pp. 403-412.

International Electrotechnical Commission (IEC), 1991. Steam turbines - part 1: Specifications. IEC 60045-1.

Koch, S., Hirsch, T., Eck, M., 2007. Modelling and control of a solarthermal parabolic trough DSG superheater with several parallel rows and central steam separation. Energy Sustainability 2007 (ES2007). Long Beach, CA (USA).

Montes, M.J., Abánades, A., Martínez-Val, J.M., 2009. Performance of a direct steam generation solar thermal power plant for electricity production as a function of the solar multiple. Solar Energy 83 (5), 679-689.

Price, H., Lupfert, E., et al., 2002. Advances in parabolic trough solar power technology. Journal of Solar Energy Engineering 124 (2), 109 125.

Valenzuela, L., Zarza, E., et al., 2005. Control concepts for direct steam generation in parabolic troughs. Solar Energy 78 (2), 301-311.

Zarza, E., Valenzuela, L., et al., 2004. Direct steam generation in parabolic troughs: final results and conclusions of the DISS project. Energy 29 (5-6), 635-644. 